\title{
Fabric Selection for Work Wear During Procurement Procedure
}

\author{
Ilze Baltina, Ausma Vilumsone, Anna Tarasenko, Liene Silina \\ Riga Technical University, Faculty of Material Science and Applied Chemistry, Institute of Design Technologies, \\ Address: Kipsalas 6 - 222, Riga, LV-1048, Latvia
}

\begin{abstract}
Nowadays, more and more importance is given to labour protection, health and safety. One of the protective means is suitable clothing. Often workwear serves as a uniform, which characterize the position of the worker and represents the organization. Basically, such types of workwear are sewn or purchased using the procurement procedure. Usually procurement procedure is carried out for the entire sewn product as a whole. When workwear is worked out great importance should be paid to basic fabrics and their protective quality. In order to provide the most suitable choice of the fabric, the procurement procedure of it should be done separately from the sewing service purchase. Fabric production and garment sewing in most cases take place at different companies. In this case, does not always match the probability that the best sewing service provider will offer the best quality fabrics.

Technical specification of fabrics should be worked out very carefully. It should include fabric fibre content, structure characteristics, type of finishing, mechanical and physical properties. Fabrics supplier selection can be made after the applicant submitted fabric technical description, were specifies all nominal values of requested technical characteristics. The procurement procedure must include testing of actual characteristics and its comparison with nominal values.

Field uniform fabrics are analysed as an example in scientific study. The procurement procedure of these fabrics should be especially accurate. During procurement procedure is important to check conformity of supplied fabric directly to offered characteristics.
\end{abstract}

Keywords: fabric, procurement procedure, work wear.

\section{INTRODUCTION}

A big part of the time is spent in a workplace. Thus, the working conditions, comfort and working tools are the ones that largely affect the quality of life and one's working capacity. Nowadays, work wear plays a very important role. It performs a variety of functions. One of the most important is the safety function, as well as representation. Workwear often serves as a uniform which also perform the tasks of protection.

The standard LVS EN ISO 31688:2013 "Protective clothing. General requirements" stipulates that protective clothing is clothing including protectors which cover or replace personal clothing, and which is designed to provide protection against one or more hazards [1]. Protective clothing shall not only provide protection against all types of threats, but also be comfortable, its' body size and design, as well as the appropriate choice of materials is of great importance. It should be done very carefully, by precisely developing appropriate requirements. It is important to not only make demands, but to observe and provide them accurately.

Sewn product procurements primarily involve sewing companies, offering both product manufacturing services, as well as providing materials for manufacturing. In most cases, for the basic material procurement procedure a technical specification and requirements are developed. The supplier, by submitting a tenderer, is required to demonstrate the compliance of the potential materials and to submit a sample. Unfortunately, the real samples are rarely tested, and the materials actually used in sewing are tested even more rarely. Mainly this kind of control is related to the damages of sewn products in order to obtain the required sample fineness of the material for testing.

Failing to test the actual materials, hidden defects whose causes are ambiguously interpreted often appear in articles over time. Consequently, it is not always clear whether the defects are caused by the wearer's fault or the defects are due to the quality of the fabric. Causes are difficult to be determined precisely, but in any case, the loser is the consumer. If the fabric's non-compliance is even determined, it is still a long and complicated process.

\section{MATERIALS AND METHODS}

The compliance of the fabric used in the supplied field uniform with the requirements of the technical specification and the sample submitted within the tender is analysed. The geometric characteristics, structural characteristics, as well mechanical and physical properties of the fabrics are experimentally determined. The fabrics are tested according to European and international test methods. The 
acquired characteristics and used test methods are summarized in Table I.

Table I

Test Methods.

\begin{tabular}{|l|l|l|l|}
\hline $\begin{array}{l}\text { Geometric and structural } \\
\text { characteristics }\end{array}$ & Test method & $\begin{array}{l}\text { Mechanical and physical } \\
\text { characteristics }\end{array}$ & Test method \\
\hline Fibre content & $\begin{array}{l}\text { European Parliament and } \\
\text { Council Regulation (EU) No. } \\
1007 / 2011[2]\end{array}$ & Tensile properties of fabric & LVS EN 13934-1:2013 [7] \\
\hline Fabric width & LVS EN 1773:2001[3] & Tear properties of fabric & LVS EN 13937-2:2001[8] \\
\hline Mass of 1m ${ }^{2}$ & LVS EN 12127:2001 [4] & Air permeability & LVS EN 9237:2001 [9] \\
\hline Warp and weft density & LVS EN 1049-2:2001 [5] & Fabric stiffness & BS 3356:1990 [10] \\
\hline Warp and weft linear density & ISO 7211-5:1984 [6] & Fabric surface wetting & LVS EN ISO 4920:2012 [11] \\
\hline & & $\begin{array}{l}\text { Fabric water - vapour } \\
\text { resistance }\end{array}$ & $\begin{array}{l}\text { LVS EN ISO 11092:2014 } \\
\text { [12] }\end{array}$ \\
\hline
\end{tabular}

\section{RESULTS AND DISCUSSION}

The geometric and structural characteristics acquired during testing are summarized in Table II.
The table also contains requirements of the technical specification raised within the procurement procedure.

Table II

Geometric And Structural Characteristics Of Fabrics

\begin{tabular}{|l|l|l|l|}
\hline Characteristics & $\begin{array}{l}\text { Requirement of the technical } \\
\text { specification }\end{array}$ & Submitted sample & Supplied fabric \\
\hline Fibre content, $\%$ & $\begin{array}{l}65 \% \text { cotton } \\
35 \% \text { polyester }\end{array}$ & Not fixed & $\begin{array}{l}63.4 \pm 3 \% \text { cotton } \\
36.6 \pm 3 \% \text { polyester }\end{array}$ \\
\hline Fabric type & Ripstop & Ripstop & Ripstop \\
\hline Fabric width, cm & $150 \mathrm{~cm} \pm 10 \%$ & 155 & 149 \\
\hline Fabric weave & Plain with rip stop & Plain with rip stop & Plain with rip stop \\
\hline Mass of $1 \mathrm{~m}^{2}, \mathrm{~g}$ & 200 & $217 \pm 11$ & $214 \pm 11$ \\
\hline Warp density, warp/10cm & Not fixed & 413 & 429 \\
\hline Weft density, weft/10cm & Not fixed & 228 & 213 \\
\hline Warplinear density, tex & Not fixed & 32,2 & 32,8 \\
\hline weft linear density, tex & Not fixed & 34,5 & 32,9 \\
\hline
\end{tabular}

The technical specification of fabrics indicates two geometrical characteristics: fabric width and weight of $1 \mathrm{~m}^{2}$.

The fabric width is indicated as $1500 \mathrm{~mm} \pm 10 \%$, which means that it can be 135 to $165 \mathrm{~cm}$ wide. Such amplitude of fabrics can cause problems during cloth construction; moreover, if the fabric is $135 \mathrm{~cm}$ wide, additional material could be necessary. When drawing up the technical specification, it would be desirable to provide a deviation amplitude that is not greater than $\pm 5 \mathrm{~cm}$ and that is not dependent on the average width (is not expressed as a percentage of the average width).

In the technical specification, a constant value is determined regarding the weight of $1 \mathrm{~m}^{2}$ of fabric $200 \mathrm{~g} / \mathrm{m}^{2}$. In fact, it is very rarely that a fabric is produced that corresponds to the value so accurately. It usually varies within $5 \%$ of the average value. Also, in this particular vase the values of both tested materials (for $1 \mathrm{~m}^{2}$ ) are slightly greater than set out in the requirements of the technical specification, but this deviation is so small that it can be ignored.
In the technical specification, two structural characteristics are determined: fibre composition and fabric type. Characteristics of both the fabric sample and the supplied fabric correspond to the set requirements. In the paper, the following structural characteristics

- Warp density in the fabric;

- Weft density in the fabric;

- Warp linear density;

- Weft linear density.

Comparing the warp and weft density of the two fabrics, we must conclude that the parameters are different, which could be due to the different fabric contraction during printing. It is the fabric width that lets us think of such a possibility. Regarding the potentially possible unevenness of yarn, the linear density of warp and weft is relatively close.

The mechanical and physical characteristic of both fabric are summarized in Table III.

Table III

Characteristics of the Fabric's Mechanical and Physical Properties

\begin{tabular}{|c|l|l|l|}
\hline Characteristics & $\begin{array}{l}\text { Requirement of the technical } \\
\text { specification }\end{array}$ & Submitted sample & Supplied fabric \\
\hline $\begin{array}{c}\text { Tensilestrength, N } \\
\bullet \quad \text { warp } \\
\text { weft }\end{array}$ & $\begin{array}{l}\text { No less than } 1050 \mathrm{~N} \\
\text { No less than } 450 \mathrm{~N}\end{array}$ & $\begin{array}{l}1106 \pm 111 \mathrm{~N} \\
552 \pm 55 \mathrm{~N}\end{array}$ & $\begin{array}{l}1260 \pm 126 \mathrm{~N} \\
547 \pm 55 \mathrm{~N}\end{array}$ \\
\hline
\end{tabular}


Environment. Technology. Resources, Rezekne, Latvia Proceedings of the $11^{\text {th }}$ International Scientific and Practical Conference. Volume III, 22-26

\begin{tabular}{|c|c|c|c|}
\hline $\begin{array}{cc}\text { Extension, } & \% \\
\bullet & \text { warp } \\
\bullet & \text { weft } \\
\end{array}$ & Not fixed & $\begin{array}{l}22,2 \% \\
11,7 \% \\
\end{array}$ & $\begin{array}{l}15,5 \% \\
12,7 \% \\
\end{array}$ \\
\hline $\begin{array}{rr}\text { Tear strength, } \mathrm{N} \\
\bullet & \text { warp } \\
\bullet & \text { weft }\end{array}$ & Not fixed & $\begin{array}{l}27 \mathrm{~N} \\
20 \mathrm{~N}\end{array}$ & $\begin{array}{l}19 \mathrm{~N} \\
15 \mathrm{~N}\end{array}$ \\
\hline $\begin{array}{l}\text { Air permeabilityat a } \\
\text { pressure difference of } 100 \mathrm{~Pa}\end{array}$ & No less than $150 \mathrm{~mm} / \mathrm{s}$ & $30 \mathrm{~mm} / \mathrm{s}$ & $22 \mathrm{~mm} / \mathrm{s}$ \\
\hline $\begin{array}{l}\text { Fabric water - vapour } \\
\text { resistance }\end{array}$ & Up to $3.5 \mathrm{~m}^{2} \mathrm{~K} / \mathrm{W}$ & $3.4 \mathrm{~m}^{2} \mathrm{~K} / \mathrm{W}$ & $4.2 \mathrm{~m}^{2} \mathrm{~K} / \mathrm{W}$ \\
\hline $\begin{array}{rr}\text { Fabric stiffness, } \\
\bullet \quad \text { warp } \\
\bullet \quad \text { weft } \\
\end{array}$ & $0.7-2.4$ & $\begin{array}{l}17 \mu \mathrm{Nm} \\
23 \mu \mathrm{Nm}\end{array}$ & $\begin{array}{l}18 \mu \mathrm{Nm} \\
49 \mu \mathrm{Nm}\end{array}$ \\
\hline Fabric surface wetting & Not fixed & Grade 1 & Grade 4 \\
\hline
\end{tabular}

The technical specification of fabrics sets the requirements for the following mechanical and physical characteristics:

- tensile strength in a longitudinal and transverse direction;

- air permeability;

- bending rigidity;

- changes of linear dimensions;

- water vapour resistance;

- thermal resistance;

- vapour permeability index.

Additional mechanical and physical characteristics set out in the paper:

- elongation;

- tear strength;

- abrasion resistance

- fabric surface wetting.

Tensile Strength indicators for both longitudinal and transverse direction correspond to the ones indicated in the technical specification. It must be taken into account that tensile strength values border values in both directions set out in the technical specification are different. Essentially, the tensile strength border value in the transverse direction is very low and therefore is not suitable for field uniforms that are work also at active physical activities. The tensile strength is tested according to the standard LVS EN ISO 13934-1. In the standard method, by simultaneously determining the tensile strength, the absolute extension of the fabric is also determined and the relative extension is calculated. Consequently, these indicators do not require investing great additional work or resources, but provide information about the fabric maximum capacity to be extended up to the breaking moment and the possible free movement during wearing. The elongation values indicated in the paperprovethe low elongation capability of the given fabric. In the recommendation of the European apparel and textile confederation EURATEX "Recommendations Concerning Characteristics And Faults in Fabrics To Be Used For Clothing" [14] it has been suggested that the trouser fabric elongation capacity should be between 12.5 and $55 \%$ in each direction. This value of the supplied fabric is close to the minimum value, but for the transverse fabric sample - even lower than the minimum allowable value. In this case, it can be concludedthat from the view of fabric prolongation this fabric is not suitable for active physical activities, where clothing is exposed to high elongation.

The technical specification does not provide requirement on the fabric tear strength. Since field uniforms are worn in active physical conditions, two investigational fabric tear strength values are defined in the paper. The values obtained are very low and are not appropriate to the product that may not restrict freemovement.

The air permeability of both the fabric sample and the supplied fabric is at least 5 time lower than required in the technical specification. Such air permeability is not allowed for clothing that is worn in active physical conditions in summer.

Vapour resistance of the fabric sample meets the values set out in the technical specification, but the value for the supplied fabric it is higher than the set value. Thus, during physical activity in warm weather conditions the fabric in the lower clothing layer accumulates a high level of humidity. Due to the high humidity, low air permeability and low tear strength of the lower clothing layer, the sewn product bends to the body, does not pass the additional strength of physical activities, and thereby breaks.

The rigidity in the transverse direction of the supplied fabric is substantially increased (more than 2 times) compared to the fabric sample. It is too large for fabrics of field uniforms. Such fabric might be unpleasant to the wearer when in contact with skin.

The surface of both the fabric sample and the supplied fabric is tested regarding its resistance against wetting. Results for both fabrics are dramatically different. If the surface of the sample fabric moistens strongly and its resistance against wetting can be evaluated with grade 1 , the surface of the supplied fabric is almost water-repellent and can be evaluated with grade 4 (see Figure 1). 


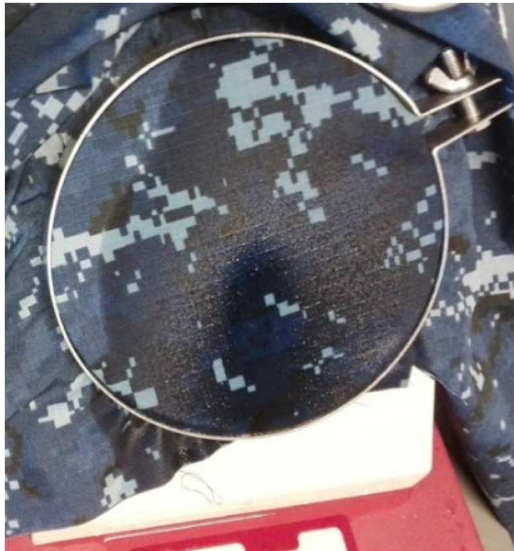

(a)

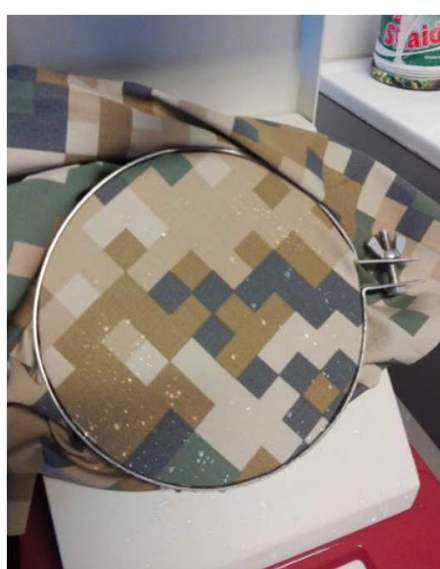

(b)

Fig. 1. Surface soaking of the fabric sample (a) and the supplied fabric (b)

Given the above, it can be concluded that neither the analysed fabric sample, nor the fabric actually used in the sewn products does not meet the requirements of the technical specification. Therefore, it can be already predicted that, first, the uniforms will outwear soon and, secondly, the wearer will feel discomfort due to the low air permeability of the fabric.

Procurement procedures of sewn product purchasing can be arranged in two ways. Traditionally, companies participate in procurements by offering ready-made products from their own materials. At the beginning, this options seems very good and acceptable, since nowadays people are usually buying manufactured foods that correspond to their needs, and only rarely purchase their own fabric and go to the tailor. By realizing manufactured goods, the manufacturer is eager to retain its customers and to as much as possible to make the customer return. In most cases customers are able to appreciate good quality. Consequently, manufacturers are interested in meeting consumer expectations with a vengeance by introducing new technologies, achievement and conclusions acquired while working.

Unfortunately, the procurement procedure focuses on one-time deals. A potential supplier is usually thinking of offering the lowest price but still meeting the minimum technical requirements set out in the specification. He does not think whether this order will be followed by another one. Materials chosen for protective work wear play an important role and they provide a large part of protective functions. Meanwhile, raw materials account for a large part of the unembroidered product's cost. Consequently, the procurements often face situations where potential suppliers offer fabrics of the lowest possible price that meet the technical specifications. Since fabric characteristics are affected by lots of different factors, ranging the smallest unit of fibre, its fineness, length, winding, thread type, coarseness, twist, fabric structure and process parameters,up to the type of finish and technological processes, it is virtually impossible for the fabric technical specification to be fully covered. Usually the most important factors are included. Unfortunately, just as in the analysed example, the suppliers not only offer the least expensive materials, but also ultimately use other similar materials, which do no longer meet the specified requirements, for sewing the products. If the supplier has to send ready-made products, it acts with confidence that the compliance of fabrics will no longer be tested, because without damaging the products in most cases it is simply not possible.

Consequently, it could be resolved by dividing the procurement into two parts. First, purchasing the fabric, testing its compliance with the requirements of the procurement procedure and the submitted sample, and then organizing a procurement for sewing services. Such a division of the procurement process would enable one toprove the protective characteristics of the material, avoid the hidden defects of the product, as well as avoid delivery of different fabrics in different delivery times. In case of army field uniforms, it would provide protection of the masking prints, originality and a narrower range of companies, to whom restricted access information should be provided.

\section{CONCLUSIONS}

Given the above analysis, we recommend to consider dividing the procurement of protective work wear into two parts: first, buying fabrics, secondly, sewing products from the purchased fabrics.

When concluding the fabric procurement, the fabrics should be tested and their conformity with technical specifications should approved mandatory.

It is important to include structural and geometric characteristics, as well as physical and mechanical propertiesin the technical specification of the fabric procurement.

Traditionally, one of the most important characteristics inthe technical specifications is fabric weight per $1 \mathrm{~m}^{2}$, but it may be equal to fabrics of a very different structure. Consequently, technical 
Environment. Technology. Resources, Rezekne, Latvia Proceedings of the $11^{\text {th }}$ International Scientific and Practical Conference. Volume III, 22-26

specification should also determine requirements for the warp and weft density or the warp and weft linear density.

The technical specification of any work wear should include such characteristics as tensile strength, elongation, tear strength, abrasion resistance, air permeability, and water vapour permeability.

\section{ACKNOWLEDGMENT}

This research work was partially financed by the European Union's European Regional Development Fund, through the INTERREG BSR Programme, which awarded a grant to the SWW project (\#R006). The authors gratefully acknowledge the received financial support.

\section{REFERENCES}

[1] LVS EN ISO 31688:2013 Aizsargapǵērbs. Vispārīgās prasības.

[2] Regulation (EU) No 1007/2011 of the European Parliament and of the Council of 27 September 2011 on textile fibre names and related labelling and marking of the fibre composition of textile products.

[3] LVS EN 1773:2001 Textiles - Fabrics - Determination of width and length
[4] LVS EN 12127:2001 Textiles - Fabrics - Determination of mass per unit area using small samples

[5] LVS EN 1049-2:2001 Textiles - Woven fabrics; construction - Methods of analysis - Part 2: Determination of number of threads per unit length

[6] ISO 7211-5:1984 TextilesWovenfabrics Construction Methodsofanalysis

[7] LVS EN 13934-1:2013 Textiles - Tensile properties of fabrics - Part 1: Determination of maximum force and elongation at maximum force using the strip method

[8] LVS EN 13937-2:2001 Textiles - Tear properties of fabrics Part 2: Determination of tear force of trouser-shaped test specimens (Single tear method)

[9] LVS EN 9237:2001 Textiles - Determination of the permeability of fabrics to air

[10] BS 3356:1990 Method for determination of bending length and flexural rigidity of fabrics

[11] LVS EN ISO 4920:2012 Textile fabrics - Determination of resistance to surface wetting (spray test)

[12] LVS EN ISO 11092:2014 Textiles - Physiological effects Measurement of thermal and water-vapour resistance under steady-state conditions (sweating guarded-hotplate test)

[13] Euratex Technical Clothing Group, "Recommendations concerning characteristics and faults in fabrics to be used for clothing," Euratex TCG Recommendations, Proposal March 2006 [Online]. Available: https://s3-eu-west1.amazonaws.com/frantic/stjm/ECLA_suositus_kankaiden_1 aatuvaatimukset 2006.pdf[Accessed: Feb. 16, 2017]. 